\title{
SEQUENCE VARIATION IN MEASLES VIRUS F GENE OF AIK-C VACCINE STRAIN AFTER PASSAGE IN VERO CELLS
}

\author{
Zohreh-Azita Sadigh $^{1,2}$, Mahmoud Shamsi Shahrabadi ${ }^{\star}$, Abbas Shafyi ${ }^{2}$, Bijan Bambai $^{3}$ \\ Virology Department of Iran University of Medical Sciences ${ }^{1}$, Razi Vaccine and Serum Research Institute ${ }^{2}$. \\ National Institute of Genetic Engineering and Biotechnology ${ }^{3}$.
}

\begin{abstract}
The live attenuated AIK-C measles virus which is used for vaccine to control measles in the world has considerably reduced the incidence of this disease.

In the present study we have cloned and analyzed the sequence of the cDNA coding for the F protein of AlK-C Vaccine Strain of Measles Virus after limited passage in Vero Cells. Comparison studies demonstrated a high degree of nucleotide sequence homology $(98 \%)$ to the AlK-C vaccine strain.Altogether four mutations were observed compared to the sequence of AlK-C vaccine strain which was reported by Mori et al and deposited in GeneBank. These mutations caused amino acid changes at position 278, 362, 419 and 549. Change from leucine to phenylalanine at position 278 of the protein that was an early event during adaptation to Vero cells, and also changes at position 362 and 419 were reported by previous study but change at position 549 wasn't report before,and must be study more.
\end{abstract}

Keywords: • MeaslesVirus $\bullet$ AlK-C vaccine strain $\bullet F$ gene $\bullet$ pDONR221 $\bullet$ Restriction Endonulease.

\section{Introduction}

$\mathrm{M}$ easles virus is a member of the order Mononegavirals, family Paramyxoviridae, genus Morbillivirus with a non segmented negative strand RNA. The $16 \mathrm{~kb}$ linear RNA econding six structural (N,P,L,H,F,M) and two non structural $(\mathrm{C}, \mathrm{V})$ proteins [1]. Two glycoproteins of hemagglutinin $(\mathrm{H})$ and fusion $(\mathrm{F})$ are present as envelope spikes and play a vital role in production of neutralizing antibody. The $\mathrm{F}$ is a type I membrane protein that is glycosylated and initially synthesized as the F0 precursor.F0 is transported to Golgi apparatus where it is cleaved by a host protease into two disulfide-linked subunits,F1 and F2.This protein is responsible for virus penetration through fusion of viral and host cell membrane, cell fusion and hemolysis .Induction of antibody responses to $\mathrm{F}$ protein is essential for protection[1,2].

Today, the live attenuated vaccines is used to control measles in the world and has dramatically

\footnotetext{
* Corresponding Author: Mahmoud Shamsi Shahrabadi, Virology Department of Medical Sciences, Rassule Akram Hospital, Nyayesh Ave, Sattarkhan St, Post Code 144561313, Tehran, Iran
}

reduced the incidence of this disease. Many developing countries still have intense MV transmission, especially in children less than 1 year of age. In these countries measles claims the lives of an estimated 700,000 infants and young children annually [3]. The measles vaccine strain AIK-C is one of the safest vaccine virus which was developed from the Edmonston strain through plaque cloning in sheep kidney cells and chick embryonic cells at $33^{\circ} \mathrm{C}$ [4] and is widely used for prevention of measles infection. Due to high effectiveness and high sero-conversion in young infants, vaccine manufacturers have attempted to produce the AIK-C measles vaccine in large scale using Vero cells. The sequential passage in these cells may have caused some changes in genome nucleotides of the virus[5].

pDONR vectors that were used in our experiment were adapted vectors designed to generate attLflanked entry clones containing a gene of interest following recombination with an attB PCR product.This vector was used for generating the expression clone by performing an LR reaction between the entry clone and a destination vector of choice like the baculovirus . 
The pDONR vectors contain the following elements rrnB $\mathrm{T} 1$ and $\mathrm{T} 2$ transcription terminators, M13 Forward and M13 Reverse priming sites for sequencing of the interest, the recombination sites(attP1 and attP2) derived from DNA recombination sites of bacteriophage $\lambda$ that allows recombinational cloning of the gene of interest from attB PCR product, $\operatorname{ccdB}$ and Chloramphenicol resistance genes located between two attP sites for negative and counter selection respectively,Kanamycin resistance gene for selection in E.coli and pUC origin for replication and maintenance of the plasmid in E.coli [6].

In the present study we have cloned and analyzed the sequence of the DNA coding for F protein of AIK-C strain of MV after three passages in Vero cells.

\section{Material and methods}

\section{Cells and virus}

Vero cells were grown in Dulbecco's modified Eagle Medium supplemented with 5\% Fetal Calf Serum and antibiotics and propagated at $37^{\circ} \mathrm{C}$. Monolayer of cells were inoculated with Measles Virus AIK-C vaccine strain provided by Dr. Abbas Shafyi (Razi Vaccine and Serum Research Institute), and inoculated at $37^{\circ} \mathrm{C}$ temperature. When cytopathic effect was observed, infected cells were harvested and stored at $-70^{\circ} \mathrm{C}$.

\section{RNA Extraction}

Infected cell cultures were centrifuged at low speed for 20 minutes.The clarified supernatant was ultracentrifuged at 20000 r.p.m for 1 hour . The pellet consisted of concentrated virus was used for RNA extraction. RNA was extracted using RNA extraction kit (RNA FAST manufactured in National Intitute of Genetic Engineering and Biotechnology).The extracted RNA was stored at $-70^{\circ} \mathrm{C}$.

\section{Primers}

Primers used for RT-PCR and PCR were designed based on published MV sequences (GeneBank accession No. S58435) and contain recombinant sites (attB1and attB2 for Forward and Reverse primers respectively shown with Bolded nucleotides) for cloning into pDONR vector. The sequence of the primers were as follow:

F-F1: 5'GGGG ACA AGT TTG TAC AAA AAA GCA GGC TCA ATG TCC ATG ATG GGT CTC 3'
F-R11:5'GGGGAC CAC TTT GTA CAA GAA AGC TGG GTA GAG CGA CCT TAC ATA GGA TT 3'

We designed also a forward primer complementary the sequence from 6022 to 6041 for thorough sequencing of the $\mathrm{F}$ gene as follow:

$\mathbf{F M}_{1}: \mathbf{5}^{\prime}$ TCC ATG GAC CAA CTA TCT TG $\mathbf{3}^{\prime}$ Amplification of the $\mathrm{F}$ gene:

Extracted RNA was used as template for reverse transcription reaction. The RT-PCR reaction was performed in a total $20 \mu$ final volume,using $2.5 \mathrm{mM}$ of each dNTPs, $100 \mathrm{\rho mol}$ of each primer, reaction buffer (containing $250 \mathrm{mM}$ Tris $\mathrm{HCl}$, $250 \mathrm{mM} \mathrm{KCl}, 20 \mathrm{mM} \mathrm{MgCl}_{2}, 50 \mathrm{mM}$ DTT), $40 \mathrm{U}$ Rnase Inhibitor, $200 \mathrm{U}$ M-Mulv Reverse Trancriptase and nuclease free water. Theremocycler was programmed for one cycle at $70^{\circ} \mathrm{Cfor} 5$ minutes, followed by one cycle at $37^{\circ} \mathrm{C}$ for 5 minutes and one cycle at $42^{\circ} \mathrm{C}$ for 60 minutes. The reaction was stopped at $70^{\circ} \mathrm{C}$ for 10 minutes and then the microtube was chilled on ice $[7,8]$.

PCR test was performed in a total of $50 \mu$ l final volume, using $1 \mathrm{ng} \mathrm{cDNA}, 10 \mathrm{\rho mol}$ of each primer, $2.5 \mathrm{mM}$ of each dNTPs, $2.5 \mathrm{mM} \mathrm{MgSo}{ }_{4}$ and 2.5 units of $p f u$ DNA polymerase[9,10]. Thermocycler was programmed for one cycle at $94^{\circ} \mathrm{C}$ for 5 minutes followed by thirty cycles at $95^{\circ} \mathrm{C}$ for 1 minutes, $52^{\circ} \mathrm{C}$ for 1 minutes, $72^{\circ} \mathrm{C}$ for 1.2 minutes and one cycle at $72^{\circ} \mathrm{C}$ for 10 minutes, as a final extention.

PCR product was electrophoresed on $1 \%(\mathrm{w} / \mathrm{v})$ agarose gel and stained by ethidium bromide and visualized by UV transluminator.

Plasmid and Construction of $\mathrm{F}$ gene Cloning vector: The pDONR221 plasmid and Omnimax chemically competent E.coli (Invitrogen) were used for cloning and sequencing.

The full coding region sequence of $F$ protein (AIKC Stain) was inserted into pDONR221, using the $\mathrm{BP}$ recombination reaction by $\mathrm{BP}$ clonase (Invitrrogen) [11].

\section{Transformation}

One vial of Omnimax chemically competent E.Coli was thawed on ice, then $1 \mu \mathrm{l}$ of BP recombination reaction were added into the vial and incubated on ice for 30 minutes. The cells were inculoated for 90 seconds at $42^{\circ} \mathrm{C}$ and the vial removed and kept in ice for 3 minutes. After that $250 \mu \mathrm{l}$ of S.O.C medium kept at room temperature was added to the vial. The vial was 
shaken horizontally at $37^{\circ} \mathrm{C}$ for 1 hour, then $50 \mu \mathrm{l}$ of the transformation mix was spread on a prewarmed selective plate (LB+Kanamycin) and incubated overnight at $37^{\circ} \mathrm{C}$ [11].

Screening the Colonies:

Clonies carrying plasmid were picked up and suspended in $5 \mathrm{ml}$ of LB broth with appropriate kanamycin concentration. Plasmids were purified from the bacteria using plasmid purification kit (Roche), and then were analyzed by Restriction Endonuclease digestion (BstX I) and sequenced with M13 primers in both direction by a dye terminator method, using the ABI 3130XL sequencer. The Nebcutter software was used for analyzing the restriction sites in PCR product and plasmids. The sequencing results were compared with other sequences deposited in the GeneBank using the BLAST software[12].

Results:

PCR amplification of cDNA from Measles Virus F gene with specific primers generated a fragment with approximately $1700 \mathrm{bp}$ in size (Fig.1).This DNA fragment product of $F$ gene was analyzed by EcoR V digestion. This gene has one restriction site for EcoRV, thus after digestion we had two fragments with sizes of approximately $1000 \mathrm{bp}$ and 700 bp (Fig 2 Lane1).

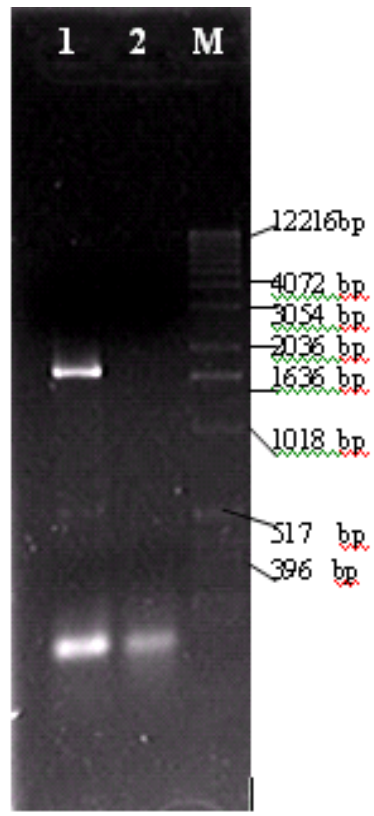

Fig-1: Amplification of $\mathrm{F}$ gene (Measles virus AlK$C$ strain). Lane1: Amplification of $F$ gene with specific.

primers (1711bp) Lane2: Negative cotral. LaneM: DNA Molecular weight Marker(0.0712.2Kbp).

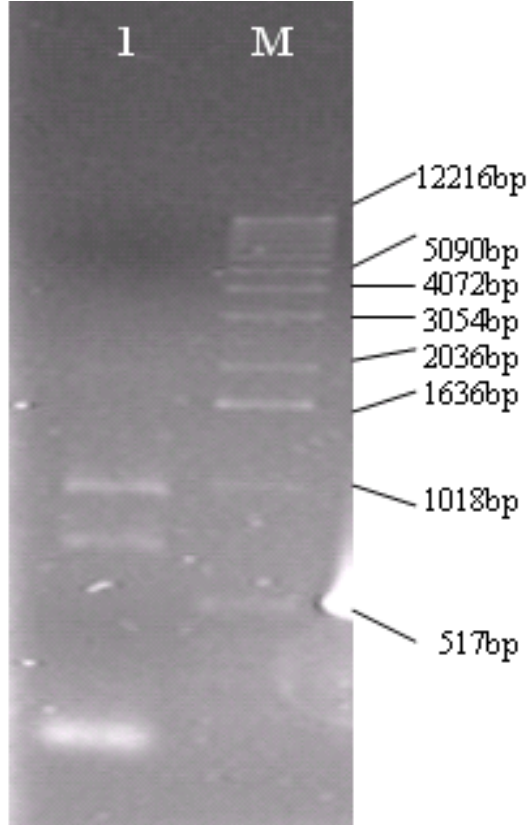

Fig-2: Digestion analysis of $\mathrm{F}$ gene with EcoRV. Lane1: Digestion analysis of PCR product of $F$ gene(711bpand1000bp). Lane M: DNA Molecular weight Marker (0.07-12.2 Kbp)

PCR product of the $\mathrm{F}$ gene was cloned into the pDONR221 by Bp recombination reaction, and these constructs were used to transform Omnimax E. coli. The presence of recombinant plasmids in the transformed colonies were screened by selection on LB agar medium containing $50 \mu \mathrm{g} / \mathrm{ml}$ Kanamycin.After plasmid purification they were analyzed by BstX I restriction enzyme.This enzyme has 2 restriction sites in the $\mathrm{F}$ gene at nucleotides 33 and 1359,but has no restriction site in nonrecombinant pDONR221(Fig.3). Therefore, after digestion we had two fragments with approximately 1300bp and 3000bp in size (Fig.4. Lane 2, 4).

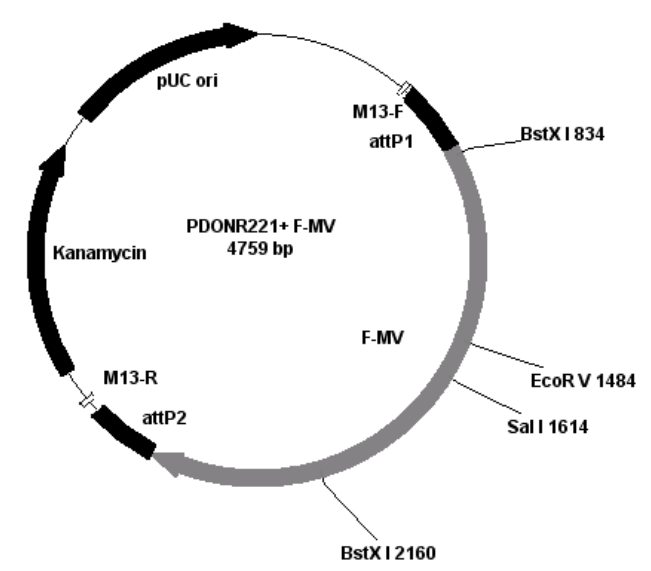

Fig-3: Schematic presentation of pDONR 221+ F gene of Measles Virus construct with some restriction sites. 


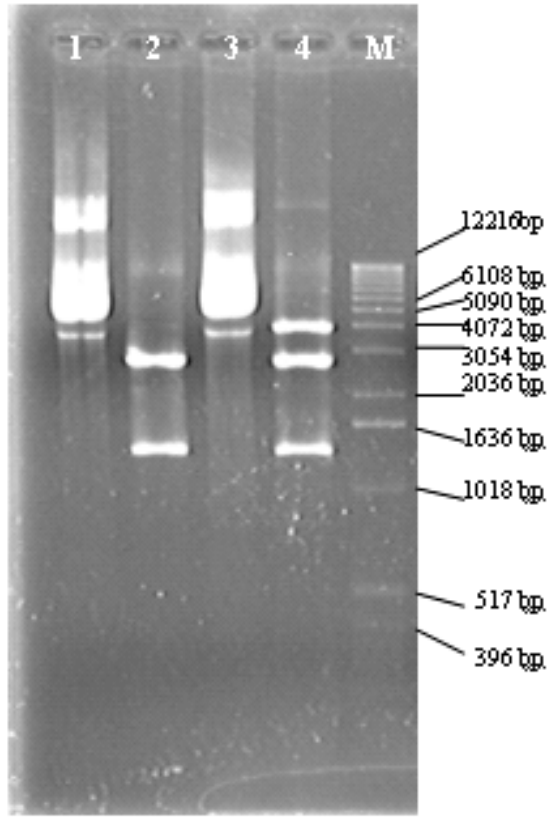

Fig-4: Confirmation of cloning of $F$ gene into pDONR via restriction enzyme analysis: Lane1: Undigested pDONR + F plasmid 1 . Lane2: digestion of pDONR221 $\mathrm{F}$ plasmid 1 with BstX I(1326bp and 3000bp). Lane 3: Undigested pDONR + F plasmid 2. Lane 4: digestion of pDONR221 + F plasmid 2 with BstX I(1326bp and 3000bp). Lane M: DNA Molecular weight marker(0.07-12.2Kbp).

The recombinant plasmids were analyzed by sequencing and the results were compared with the sequences of AIK-C strain of attenuated Measles Virus in the GeneBank 9S58435, Mori et al 1993)[13] using the BLAST Software [12]. Nucleotide comparison showed 4 differences between original AIK-C vaccine strain and AIK-C vaccine strain which passaged in Vero cells (Fig.5).

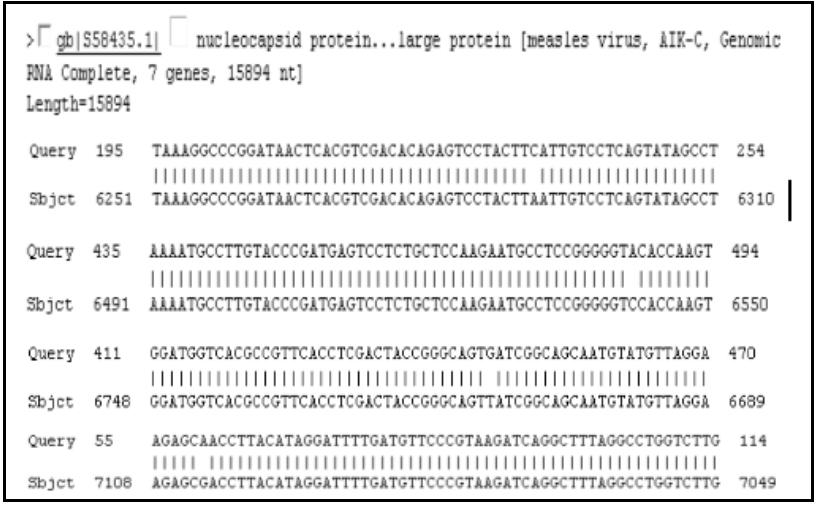

Fig-5: Sequence comparison of measles virus AIK$C$ vaccine strain (subject) and AlK-C vaccine strain which were passaged 3 times in Vero cells. (Query).
These nuclesotide substitution led to 4 amino acid substitution in the $\mathrm{F}$ protein (Leucin to phenylalanine at position 278; F278-Phe, Serine to Tyrosine at position 362; F362-Tyr, Histidine to Asparagine at position 419;F419-Asn and serine to Leuicne at position 549; F549-Leu).

\section{Discussion}

Most RNA viruses are considered to be a mixture of hetrogenous viruses becuase of their high incidence of mutation in the RNA genome in nature [14]. Certain viruses such as measles are antigenically stable, whereas others readily give rise to antigenic variants [15]. Analyses of the MV genes of a large number of strains have established that the F gene is highly stable, and up to 1989 only three amino acid changes have been observed in the Edmonston strain and related isolates [16]. The measles vaccine strain AIK-C which was developed from the Edmoston strain which has been attenuated in lamb kidney cells and cloned in chick firoblast cells at $33^{\circ} \mathrm{C}$ [4], are widely used for prevention of measles infection in the world [5]. Because of the high effectiveness of vaccination program and low incidence of adverse reaction and high sero-conversion in young infants, a vaccine manufacturer decided to produce the AIK-C measles vaccine in large scale using Vero cells [15]. In this regards a group of investigators studied the genetic stability of the virus and reported that there was three amino acid changes in the F gene [17]. In this study AIK-C vaccine strain was passeaged 3 times in Vero cells in order to amplify the $\mathrm{F}$ gene. We observed 4 amino acid substitution which were different from those reported by previous studies [17].A likely explanation of these differences lies in the types of tools and methods used to analyzed the virus genome . Another difference lay in the passage history of the sequenced AIK-C viruses, because here the virus was passaged three times in Vero cells, whereas Mori et al used chicken embryo cells[18]. Change from leucine to phenylalanine at position 278 of the F protein was the first mutation occurred during the viral passage in Vero cells. The extent of these genome variation on viral properties remains to be determined. 


\section{Sequence variation in measles virus $\mathrm{F}$ gene of AlK-C vaccine ...}

\section{References}

1 Griffin, D.E, 2001. Measles virus, p.1401-1428. In B.N. Fields, O.M Knipe, P.M. Howely, Fields virology $4^{\text {th }}$ ed Lippincott Williams and Wilkins publishers.

2 Atabani,

S.F.,Obeid,O.E.,Chargelegue,D.,Abbay,P.,Whittle,H., Stward, M.W.1997. Identification of an Immunodominant neutralizing and protective epitope from measles virus fusion protein by using human sera from acute infection J.virol 71:7240-7245.

3 Premenko - Lanier, Hodag, G.,Rota, P., Tamin, A.,Bellini,W.,McChesney,M.2006. Maternal antibody inhibits both cellular and humoral immunity in response to measles vaccination at birth. Virology.2006 Jul 5;350(2):429-32.

4 Sassaki. K.1974. studies on the modification of the live AIK measles vaccine I- adaptation of the further attenuated AIK measles virus (The strain of AIK-L33) to chick embryo cells. Kitasato Arch. Exp.Med .47:1-12.

5 Komase,K., Nakayama,T., Iijima,M., Miki,K., Kawanishi,R., Uejima,H. 2006. The phosphoprotein of attenuated measles AIK-C vaccine strain contributes to its temperature-sensitive phenotype.Vaccine.24:826-834.

6 Gateway pDONR vectors. Version C .15 Jul 2004.

7 Protocol for First Strand cDNA Synthesis( PCR template generation with M-MuLV Reverse Trascriptase) Fermentas.

8 Verma,I.M.1981.Reverse transcriptase.The Enzymes (Boyer,P.D.,ed), Academic Press Inc., Vol.14:87-103.

9 Protocol for PCR with $p f u$ DNA polymerase Fermentas.
10 Lundberg, K.S.,et al.1991. High- fidelity amplification using a thermostable DNA polymerase isolated from Pyrococcus furiosus, Gene, 108:1-6.

11 Gateway Technology with Clonase II.Version A. 24 June 2004 Invitrogen.

12 Atschul,S.F., Madden,T.L.,Schaffer, A.A. Zhang,J.,Zhang,Z.,Miller.W.,Lipman,D. 1997.'Gapped BLAST and PSI-BLAST:a new generation of protein database search programs",Nucleic Acids Res.25:33893402 .

13 Mori,T., Sassaki,K.,Hohimoto,H.,Makino,S. 1993. Molecular cloning and complete nucleotide sequence of the genomic RNA of the AIK-C strain of attenuated measles virus.Virus Genes.7:67-81.

14 Domingo,E., Ruiz-Jarab,CM., Sierra,S.,Arias,a., Pariente,N., Baranowski,E. 2002. Mini Review. Emergence and selection of RNA variants: memory and extinction. Virus Res.82:39-44.

15 Rota,J.S., Rota,P.A., Redd,S.B.,Redd,s.c.,Pattamadilok,S.,Bellini,W.J.1998. Genetic analysis of measles viruses isolated in the United States,1995-1996.J.Infect. Dis. 177:204-208.

16 Rota,J,S., Hummel,K.B., Rota,P.A., Bellini,W.J. 1992. Genetic variability of the glycoprotein genes of current wild-type measles isolates.Virology.188:135-142.

17 Uejima,H., Nakayama,T., Komase,K. 2006. Passage in Vero cells alters the characteristics of measles AIK-C vaccine strain.Vaccine. 24:931-936.

18 Parks,C.L.,Lerch,R.A.,Walpita,P.,Wang,HP.,Sidhu,M.S.,Udem,S.A.2001. Comparison of predicted amino acid sequences of Measles Virus Strains in the Edmonston Vaccine Lneage.J.Virol.75:910-920. 